Article

\title{
Alginate-Derived Oligosaccharide Inhibits Neuroinflammation and Promotes Microglial Phagocytosis of $\beta$-Amyloid
}

\section{Rui Zhou ${ }^{1}$, Xu-Yang Shi ${ }^{2}$, De-Cheng Bi ${ }^{1}$, Wei-Shan Fang ${ }^{2}$, Gao-Bin Wei ${ }^{2}$ and Xu Xu ${ }^{1, *}$}

1 Shenzhen Key Laboratory of Marine Bioresources and Ecology, Collage of Life Science, Shenzhen University, Shenzhen 518060, China; E-Mails: zhouruiswg@gmail.com (R.Z.); bidecheng@foxmail.com (D.-C.B.)

2 College of Life Science, Shenzhen Key Laboratory of Microbial Genetic Engineering, Shenzhen University, Shenzhen 518060, China; E-Mails: shixuyang075@gmail.com (X.-Y.S.); fangweishan90@163.com (W.-S.F.); weigaobin@126.com (G.-B.W.)

* Author to whom correspondence should be addressed; E-Mail: xuxu@szu.edu.cn; Tel.: +86-755-26534977; Fax: +86-755-26534274.

Academic Editor: Paola Laurienzo

Received: 17 July 2015 / Accepted: 7 September 2015 / Published: 16 September 2015

\begin{abstract}
Alginate from marine brown algae has been widely applied in biotechnology. In this work, the effects of alginate-derived oligosaccharide (AdO) on lipopolysaccharide (LPS)/ $\beta$-amyloid (A $\beta$ )-induced neuroinflammation and microglial phagocytosis of $A \beta$ were studied. We found that pretreatment of BV2 microglia with AdO prior to LPS/A $\beta$ stimulation led to a significant inhibition of production of nitric oxide (NO) and prostaglandin $\mathrm{E}_{2}\left(\mathrm{PGE}_{2}\right)$, expression of inducible nitric oxide synthase (iNOS) and cyclooxygenase-2 (COX-2) and secretion of proinflammatory cytokines. We further demonstrated that AdO remarkably attenuated the LPS-activated overexpression of toll-like receptor 4 (TLR4) and nuclear factor (NF)- $\mathrm{B}$ in BV2 cells. In addition to the impressive inhibitory effect on neuroinflammation, we also found that AdO promoted the phagocytosis of $A \beta$ through its interaction with TLR4 in microglia. Our results suggested that $\mathrm{AdO}$ exerted the inhibitory effect on neuroinflammation and the promotion effect on microglial phagocytosis, indicating its potential as a nutraceutical or therapeutic agent for neurodegenerative diseases, particularly Alzheimer's disease (AD).
\end{abstract}

Keywords: alginate; $\beta$-amyloid; microglia; neuroinflammation; phagocytosis; toll-like receptor 4 


\section{Introduction}

In the last decade, increasing evidence has demonstrated that neuroinflammation is involved in the pathogenesis and progression of various neurodegenerative disorders, including Alzheimer's disease (AD) [1] and Parkinson's disease [2]. The accumulation of $\beta$-amyloid $(A \beta)$ and the accompanying neurotoxicity is considered to be one of the most important pathologies of AD [3]. Microglial cells are resident immune cells and act as effectors of various processes in normal and pathological brains. Two of the main functions of microglial cells are mediating neuroinflammation and clearing toxic $\mathrm{A} \beta$ aggregates via phagocytosis [4]. Previous reports have proposed that activated microglial cells are induced by pathogen-associated environmental toxins, such as lipopolysaccharide (LPS) or A $\beta$ [5]. LPS/A $\beta$ activates microglial cells via various receptors expressed on the cell surfaces, especially toll-like receptors (TLR) [6]. TLR activation of the microglial cells induce the secretion of a number of inflammatory factors that lead to cytotoxic effects and brain damage, resulting in serious neuroinflammation [7,8]. The TLR4 signaling that triggers the generation of the inflammatory mediators depends on the activation of multiple intracellular signaling pathways, including nuclear factor (NF)- $\mathrm{KB}$ and mitogen-activated protein kinases (MAPKs) [6,9]. It has been established that agents that can efficiently attenuate TLR signaling and decrease the inflammatory responses of the activated microglial cells are beneficial in treating $\mathrm{AD}$ [10]. In addition, microglia are essentially the macrophages of the brain, and phagocytosis is a key feature of these cells. This function supports brain homoeostasis by clearing neurotoxic substances, including cellular debris and $\mathrm{A} \beta$ aggregates. However, it has been found that the clearance of toxic $A \beta$ aggregates by the microglia is impaired in $\mathrm{AD}$ [11]. Considering the inflammatory and phagocytotic functions of microglia, one possible therapeutic method for treating $\mathrm{AD}$ is to reduce microglia-mediated neuroinflammation and increase microglial clearance of $A \beta[12]$.

Alginate derived from various marine brown algae is an acidic polysaccharide composed of alternating blocks of $\beta$-(1-4)-D-mannuronic acid (M) and $\alpha$-(1-4)-L-guluronic acid (G). Alginate has been widely applied in biotechnology for microencapsulation, drug delivery, and tissue engineering [13,14]. Alginate-derived oligosaccharide (AdO) produced by depolymerizing the polysaccharide using various degradation methods shows a variety of biological activities. Unsaturated AdO depolymerized by enzymatic depolymerization exerts anti-tumor [15], anti-oxidant [16,17], and immunomodulatory effects $[18,19]$, whereas the saturated AdO prepared by acid hydrolysis posses low bioactivities. The anti-inflammatory activities of alginate have been described [20,21]. AdO prepared by oxidative degradation possibly has a carboxyl group at the 1-position of the reducing end, which have been characterized in the previous work (Figure 1) [22]. We have demonstrated that AdO prepared by oxidative degradation suppressed the inflammatory response in LPS-activated marine macrophage RAW 264.7 cells [23], which inspired us to investigate whether AdO could reduce neuroinflammation and subsequently attenuate neuroinflammation-mediated diseases.

In the current study, our aim is to investigate the molecular mechanisms of the inhibitory effect of AdO on LPS/A $\beta$-stimulated microglial neuroinflammation, and to demonstrate the effect of AdO on the phagocytosis of A $\beta$ by BV2 microglia. Our findings suggested the potential application of AdO as a therapeutic agent for the treatment of AD. 


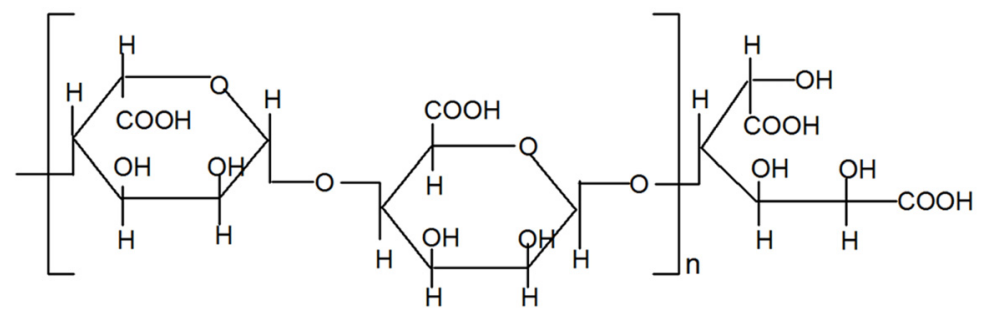

Figure 1. Schematic representation of chemical structures of alginate-derived oligosaccharide $(\mathrm{AdO})$ prepared by oxidative degradation.

\section{Results}

\subsection{AdO Suppresses LPS-Induced Production of Inflammatory Mediators in BV2 Cells}

To evaluate the toxicity of AdO to BV2 cells, the cell viability was measured after treatment with AdO. Results showed that AdO with concentrations lower than $500 \mu \mathrm{g} / \mathrm{mL}$ led to little cytotoxic effect in BV2 cells (Figure 2A). Therefore, we investigated the anti-neuroinflammatory effect of $50-500 \mu \mathrm{g} / \mathrm{mL}$ of AdO in LPS-activated BV2 cells in this study. Next, we evaluated the effect of AdO on the production of nitric oxide $(\mathrm{NO})$ and prostaglandin $\mathrm{E}_{2}\left(\mathrm{PGE}_{2}\right)$ by LPS-activated BV2 cells. As shown in Figure $2 \mathrm{~B}$ and $\mathrm{C}, \mathrm{AdO}$ at various concentrations inhibited the LPS-induced $\mathrm{NO}$ and $\mathrm{PGE}_{2}$ levels in BV2 cells in a dose-dependent manner. On the basis that inducible nitric oxide synthase (iNOS) and cyclooxygenase-2 (COX-2) are the key enzymes for production of $\mathrm{NO}$ and $\mathrm{PGE}_{2}$, respectively, we performed RT-PCR and Western blot analyses to determine the effects of AdO on the expression of iNOS and COX-2. The results showed that the LPS-induced expression of iNOS and COX-2 was suppressed by AdO treatment at the mRNA level (Figure 2D, E) and at the protein level (Figure $2 \mathrm{~F}, \mathrm{G}$ ). These results indicated that $\mathrm{AdO}$ reduces $\mathrm{NO}$ and $\mathrm{PGE}_{2}$ production by inhibiting the iNOS and COX-2 expression.

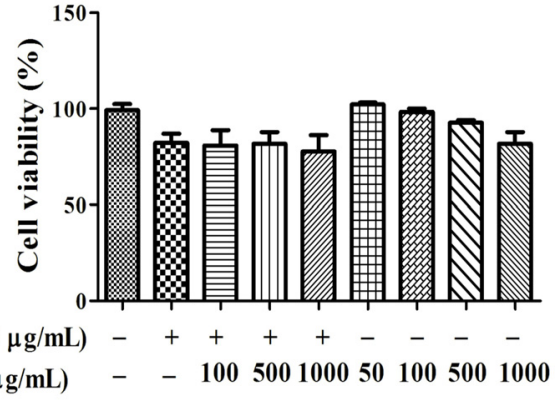

(A)

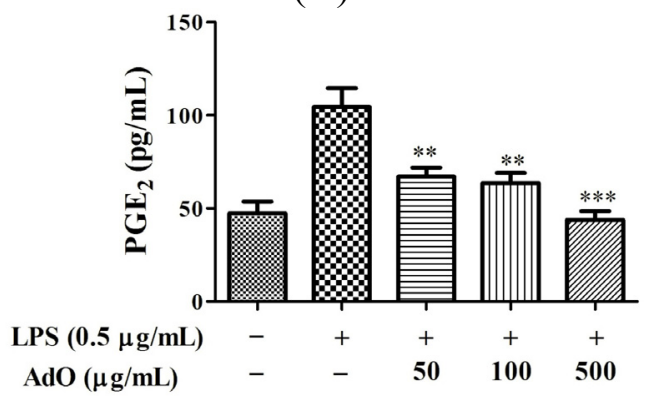

(C)

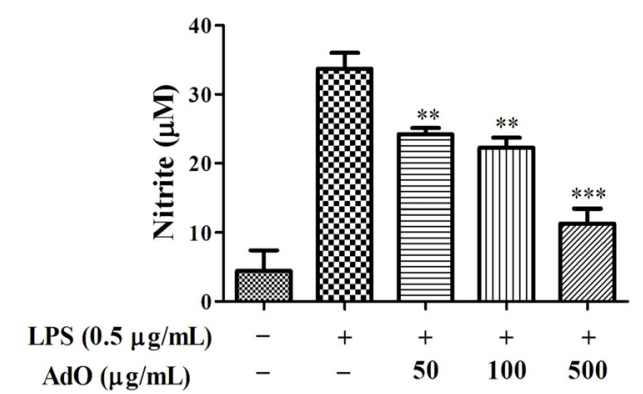

(B)

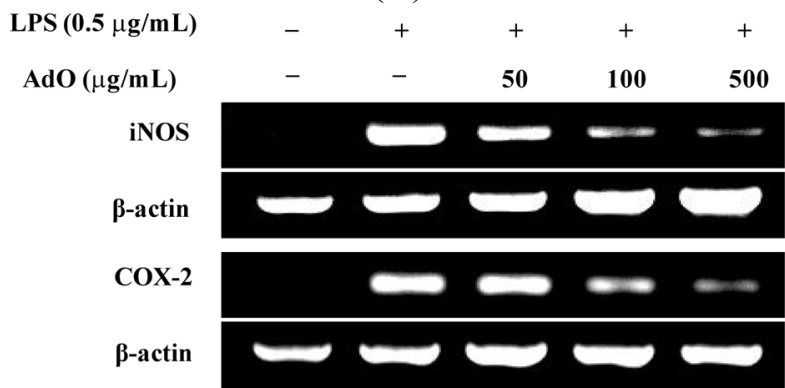

(D)

Figure 2. Cont. 


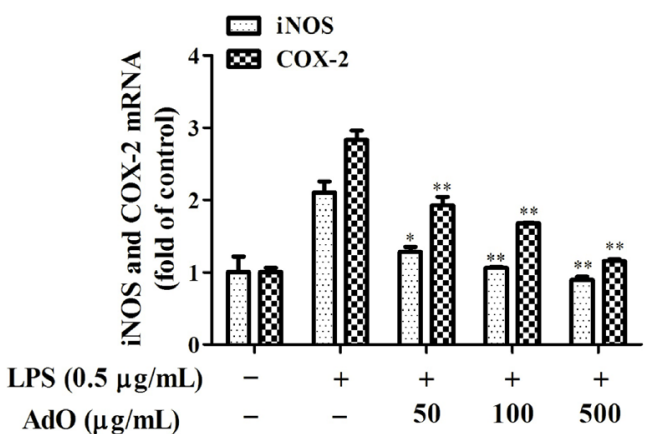

(E)

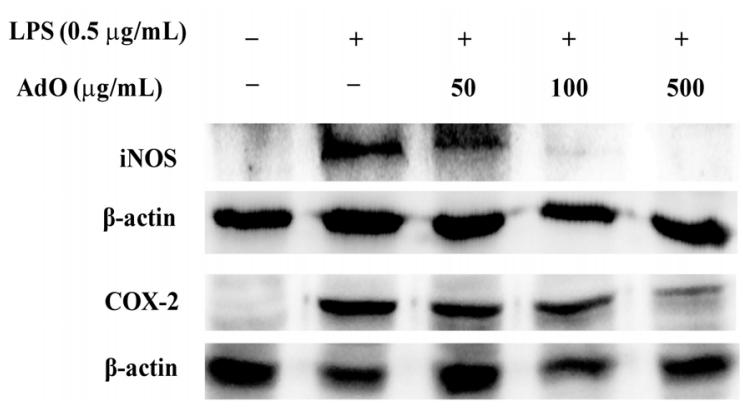

(F)

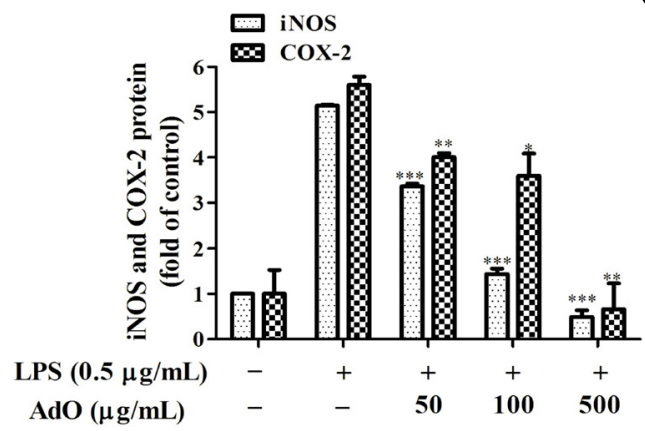

(G)

Figure 2. AdO reduced the lipopolysaccharide (LPS)-activated production of nitric oxide (NO) and prostaglandin $\mathrm{E}_{2}\left(\mathrm{PGE}_{2}\right)$ and the expression of inducible nitric oxide synthase (iNOS) and cyclooxygenase-2 (COX-2) in BV2 microglial cells. (A) Cell viability was evaluated using the CCK-8 assay for control cells, LPS $(0.5 \mu \mathrm{g} / \mathrm{mL})$ treatment cells, LPS with AdO $(100-1000 \mu \mathrm{g} / \mathrm{mL})$ treatment cells, and $\mathrm{AdO}(50-1000 \mu \mathrm{g} / \mathrm{mL})$ treatment cells; (B) The nitrite concentration was measured as an indicator of NO production using the Griess reagent; (C) $\mathrm{PGE}_{2}$ production was analyzed using ELISA; (D) The expression of the iNOS and COX-2 mRNAs was detected by RT-PCR; (E) The relative mRNA levels of iNOS and COX-2 were analyzed with reference to the control group; $(\mathbf{F})$ The expression of the iNOS and COX-2 proteins was detected using Western blot analysis; (G) The relative levels of the iNOS and COX-2 proteins were analyzed with reference to the control group. The data are presented as the mean \pm SD for three independent experiments. ${ }^{*} p<0.05$, ** $p<0.01$ and $* * * p<0.001$ indicate significant differences compared with the LPS-treated group.

\subsection{AdO Inhibits LPS/A $\beta$-Activated Secretion of Inflammatory Cytokines in BV2 Cells}

As demonstrated in Figure 3, the secretion of tumor necrosis factor- $\alpha$ (TNF- $\alpha$ ), interleukin (IL)-1 $\beta$ and IL-6 (Figure 3A) was notably increased with LPS stimulation, but considerably decreased in a dose-dependent manner in the AdO-pretreated cells. Next, we investigated whether AdO could affect the $A \beta$-activated production of the inflammatory cytokines by the BV2 cells. As expected, the results showed that the AdO treatment remarkably reduced the A $\beta$-stimulated production of TNF- $\alpha$, IL- 6 and IL-12 (Figure 3B). Interestingly, we demonstrated that $A \beta$ reduced the cell viability to $76.6 \% \pm 3.36 \%$, but pre-treatment with $\mathrm{AdO}$ exerted a positive effect on the cell viability (Figure 3C). These results 
suggest that AdO could effectively suppress the LPS/A $\beta$-activated inflammatory cytokines secretion by the BV2 cells.

A

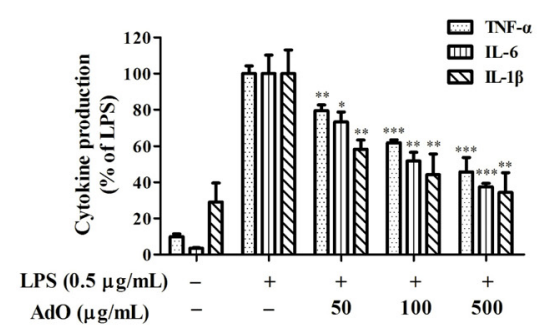

B

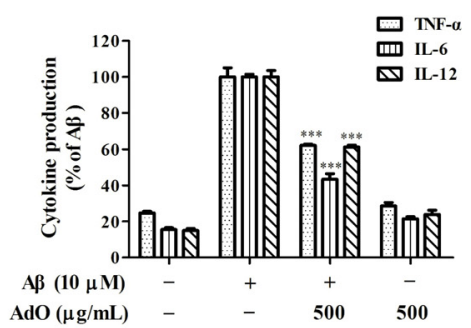

C

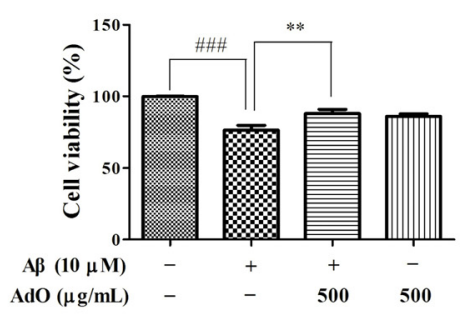

Figure 3. AdO inhibited the LPS/A $\beta$-activated secretion of proinflammatory cytokines. (A) Tumor necrosis factor- $\alpha$ (TNF- $\alpha$ ), interleukin (IL)-1 $\beta$ and IL-6 expression in the LPS-activated BV2 cells was measured by ELISA; (B) TNF- $\alpha$, IL-6 and IL-12 production in the A $\beta$-activated BV2 cells was evaluated by ELISA; $(\mathbf{C})$ The cell viability following $\mathrm{AdO}(500 \mu \mathrm{g} / \mathrm{mL})$ pretreatment with or without $\mathrm{A} \beta(10 \mu \mathrm{M})$ stimulation was detected by the CCK- 8 assay. The data are presented as the mean \pm SD for three independent experiments. $* p<0.05, * * p<0.01$ and $* * * p<0.001$ indicate significant differences compared with the LPS/A $\beta$-treated group, and \#\#\# $p<0.001$ indicates a significant difference between the control group and the $A \beta$-treated group.

\subsection{AdO Inhibits LPS-Activated Signaling Pathway in BV2 Cells}

Next, we evaluated the effect of AdO on the LPS-activated TLR4-NF- $\kappa B$ signaling pathway using immunofluorescence and Western blot analysis. As shown in Figure 4A, TLR4 expression was notably increased by LPS stimulation, and this effect was blocked by the addition of AdO. Similar results were observed in the Western blot analysis (Figure 4B). Figure 4C clearly shows that the translocation of the $\mathrm{NF}-\kappa \mathrm{B} / \mathrm{p} 65$ subunit from the cytoplasm to the cell nucleus was augmented by LPS-stimulation and reduced by AdO treatment. The results of the Western blot analysis agreed well with the immunofluorescence analysis (Figure 4D).

\subsection{Effect of AdO on LPS/AB-Activated Morphological Changes of the BV2 Cells}

Furthermore, it has been demonstrated that anti-inflammatory agents can protect the microglia from LPS or A $\beta$-activated morphological changes [24,25]. Here, the effect of AdO on the LPS/A $\beta$-activated cell morphological changes was observed using dark-field microscopy. The enlargement of microglial cell bodies and an amoeboid morphology with retraction of extensions are generally induced by LPS [24]. While these changes were obvious in the LPS-activated BV2 microglia (see white dot arrows in Figure 5A), AdO markedly suppressed those morphological changes (Figure 5A). We analyzed the number of cells with normal (white arrows) or activated (white dot arrows) morphology in ten randomly selected images. The results showed that pretreatment with AdO prevented the LPS-activated morphological changes of the cells in a dose-dependent manner (Figure 5B). In addition, the effect of $\mathrm{AdO}$ on the $\mathrm{A} \beta$-activated microglia morphological changes was investigated. As 
expected, $\mathrm{AdO}$ protected the microglia from the $\mathrm{A} \beta$-activated morphological changes (Figure $5 \mathrm{C}$ ). The analyzed results are shown as histograms (Figure 5D).

A

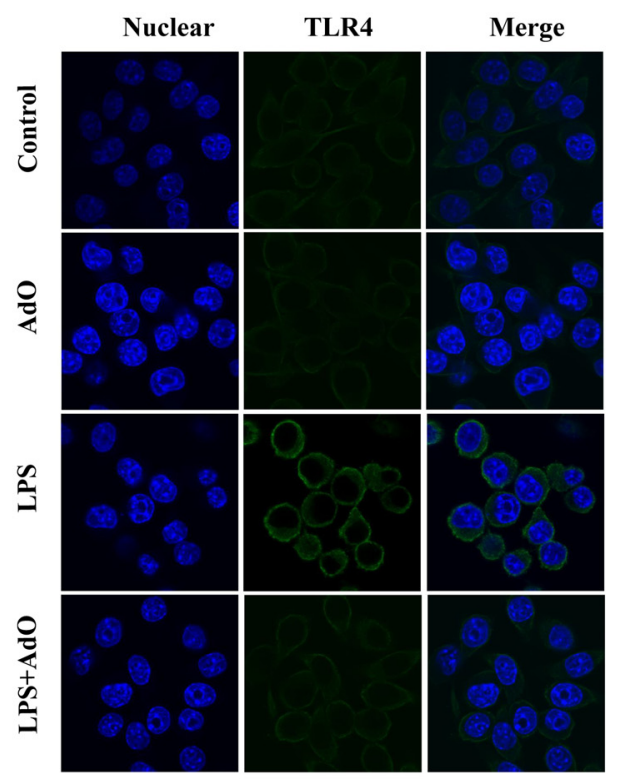

$\mathrm{B}$

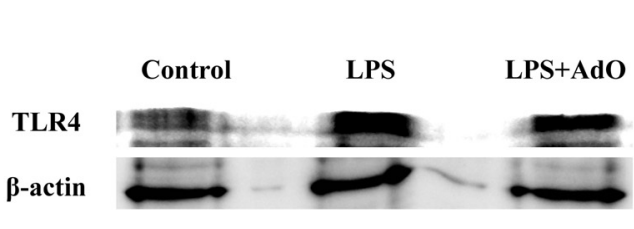

\section{$\mathrm{C}$}

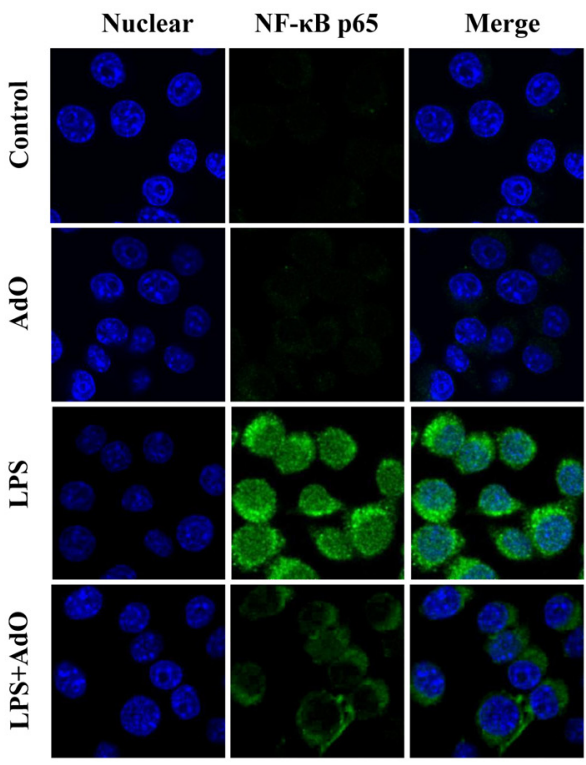

$\mathrm{D}$

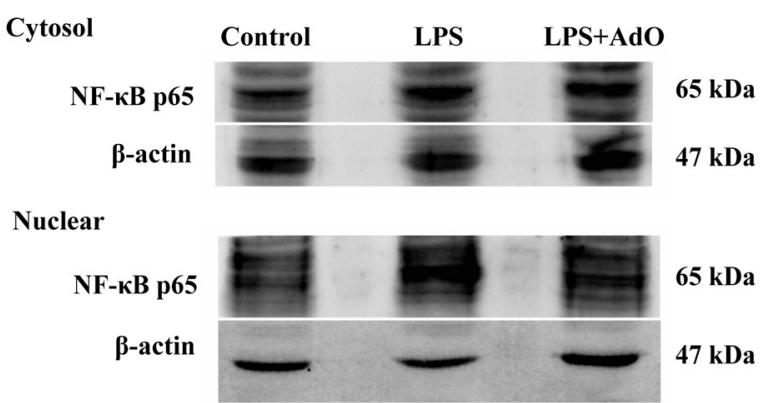

Figure 4. AdO suppressed the LPS-induced toll-like receptor 4 (TLR4) expression and nuclear factor (NF)- $\mathrm{kB}$ activation. TLR4 expression was evaluated using immunofluorescence analysis (A) and Western blot analysis (B); (C) NF-kB p65 expression was examined using immunofluorescence analysis; (D) The cytoplasm and

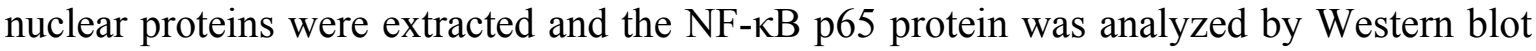
analysis. The immunofluorescence analysis was carried out by laser scanning confocal microscopy $(60 \times)$, and the images were processed using ImageJ software. The immunofluorescence analysis and Western blot analysis were performed in three independent experiments. 
A
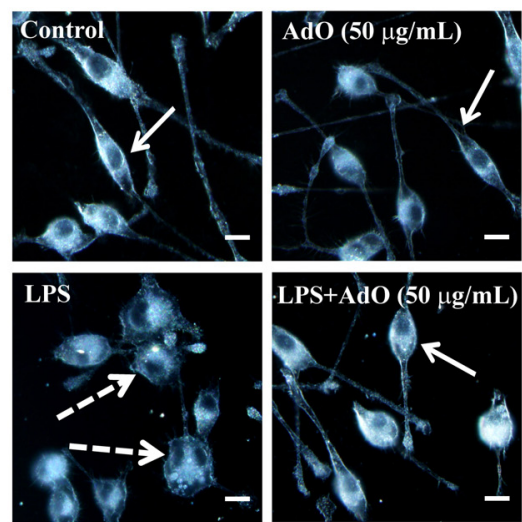

C
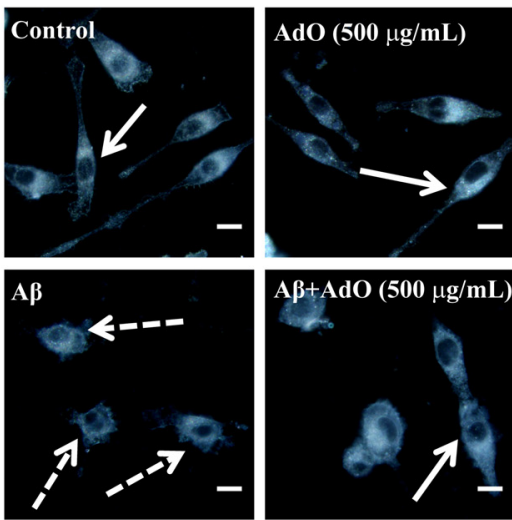

$\mathrm{A \beta}+\mathrm{AdO}(\mathbf{5 0 0} \mu \mathrm{g} / \mathrm{mL})$

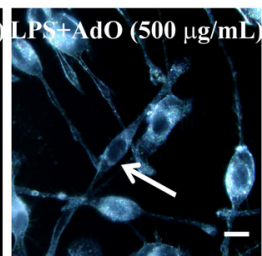

D

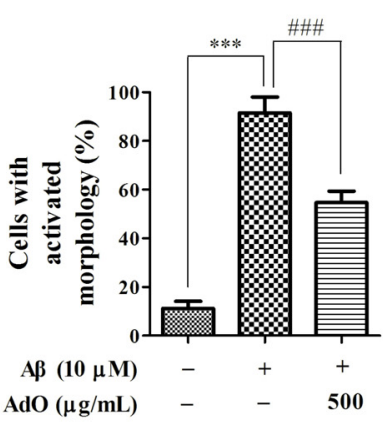

Figure 5. AdO inhibited the morphological changes induced by LPS/ $\beta$-amyloid $(A \beta)$ in the BV2 cells. (A) The cellular morphology of the control group, AdO (50-500 $\mu \mathrm{g} / \mathrm{mL})$-treated group, LPS $(0.5 \mu \mathrm{g} / \mathrm{mL})$-treated group and the group treated with AdO prior to LPS are shown in the dark field images; (B) The percentage of cells exhibiting the activated morphology was statistically analyzed; (C) The cellular morphology of the control group, $\mathrm{AdO}(500 \mu \mathrm{g} / \mathrm{mL})$-treated group, and $\mathrm{A} \beta(10 \mu \mathrm{M})$-treated group as well as the group treated with AdO prior to $A \beta$ are shown in the dark field images; (D) The percentage of cells exhibiting the activated morphology was statistically analyzed. The cellular morphology was observed using dark-field microscopy $(40 \times)$, and the images were analyzed using ImageJ software (National Institutes of Health, Bethesda, MD, USA). The normal cell morphology is indicated by white arrows, and the activated cell morphology is indicated by white dotted arrows. Scale bar $=20 \mu \mathrm{m}$. The images were from three independent experiments. ${ }^{* * *} p<0.001$ indicates significant differences between the control group and the LPS/A $\beta$-treated group; \#\#\# $p<0.001$ indicates significant differences between the LPS/A $\beta$-treated group and the group treated with AdO prior to LPS/A $\beta$. 


\subsection{AdO Promotes the Phagocytosis of A $\beta$ in BV2 Cells}

First, gold nanoparticles (AuNPs) with a 100-nm diameter were used to evaluate the non-specific phagocytic ability of BV2 cells. The BV2 microglia were incubated with AuNPs for the indicated times and observed using dark-field microscopy. The cells with phagocytosed AuNPs are shown in Figure 6A. The intracellular AuNPs were analyzed using ImageJ software. The results showed that BV2 microglia readily accumulated increasing amounts of AuNPs in a time-dependent manner (Figure 6B). Next, the BV2 cells were treated with AdO for $20 \mathrm{~h}$, after which AuNPs were added, and the incubation was continued for an additional $1 \mathrm{~h}$. We found that the BV2 cells treated with AdO accumulated more AuNPs than the untreated cells (Figure 6C). The analyzed results are shown in Figure 6D. AdO treatment increased the phagocytosis of AuNPs in a concentration-dependent manner, suggesting that $\mathrm{AdO}$ activated the BV2 microglia and promoted phagocytosis. In addition, the results clearly showed that AdO promoted the uptake of AuNPs in a concentration-dependent manner at the single cell level (Supplementary information Figure S1). These results demonstrated that AdO could promote non-specific phagocytosis in microglia. Next, Hilyte Fluo ${ }^{\text {TM }} 488$-labled $\beta$-amyloid (1-42) (FL-A $\beta$ ) was used to evaluate the specific phagocytic ability of BV2 cells. We utilized fluorescence analysis to determine the effect of $\mathrm{AdO}$ on the microglial phagocytosis of FL-A $\beta$. As shown in Figure $6 \mathrm{E}$, the control cells engulfed a small amount of FL-A $\beta$, whereas the AdO-treated cells accumulated a larger amount of FL-A $\beta$. Compared to the fluorescence $(16.6 \pm 5.9)$ of the untreated cells, the AdO treatment of the cells promoted the uptake of FL-A $\beta$ up to two-fold $(36.7 \pm 8.6)$ (Figure $6 \mathrm{~F})$.
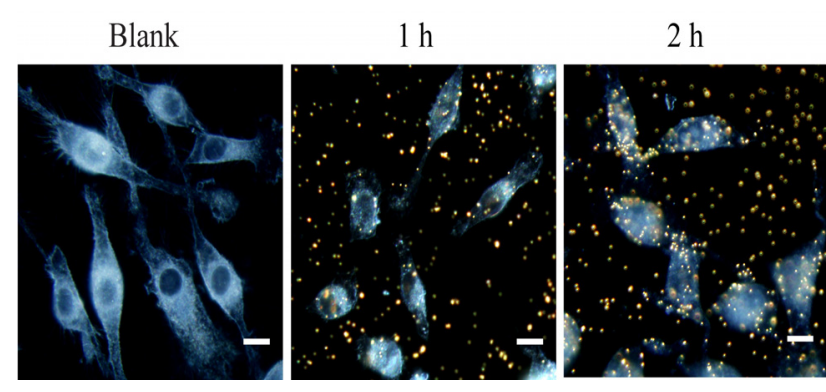

(A)
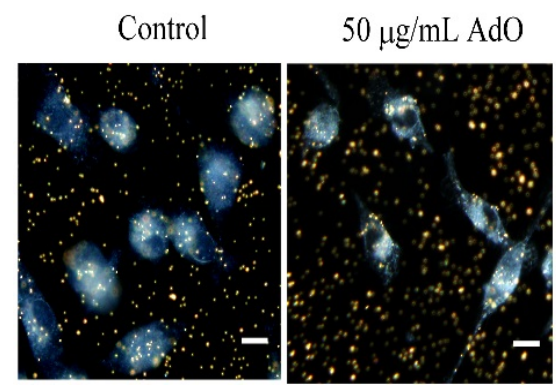

(C)
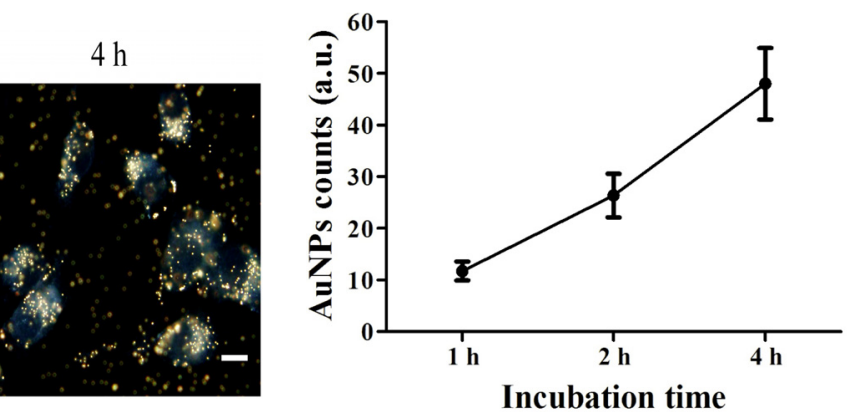

(B)

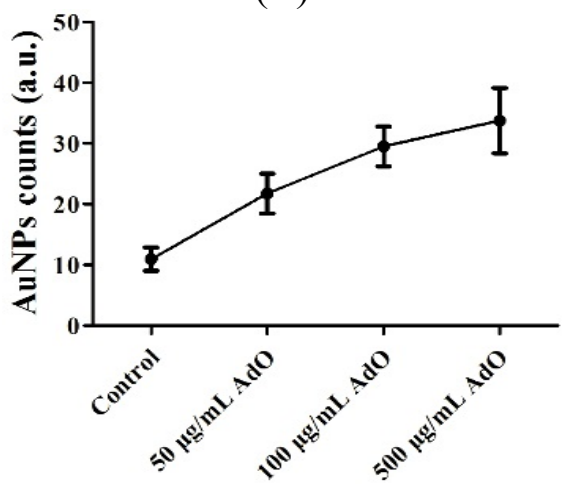

(D)

Figure 6. Cont. 


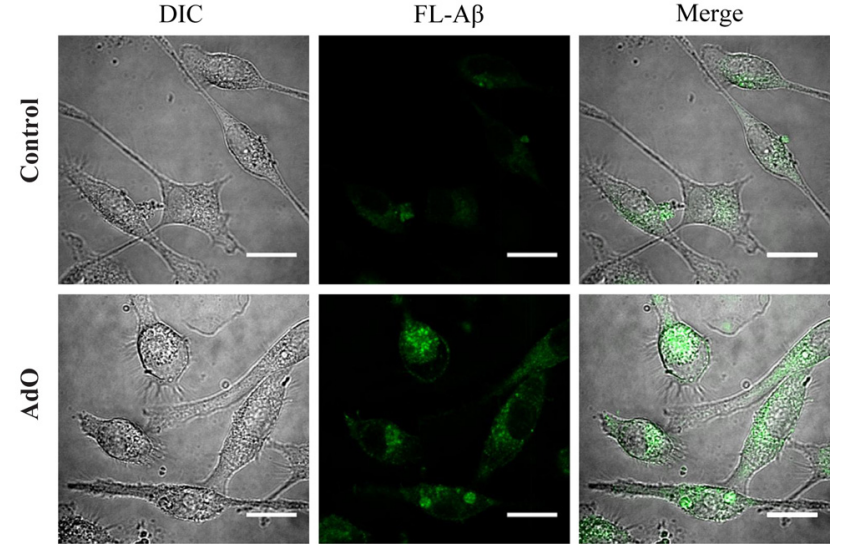

(E)

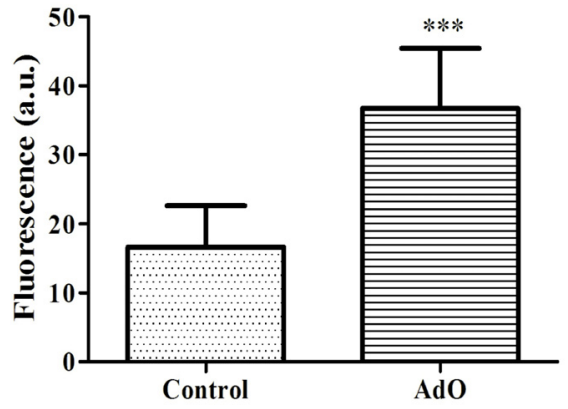

(F)

Figure 6. AdO promoted the phagocytosis of gold nanoparticles (AuNPs) and Hilyte Fluo $^{\text {TM }} 488$-labled $\beta$-amyloid (1-42) (FL-A $\beta$ ) in the BV2 cells. (A) The cells were treated with $1 \mathrm{pM}$ of the AuNPs for indicated incubation times; (B) The phagocytosis of the AuNPs by the BV2 cells was evaluated by counting the number of AuNPs in fifty cells using ImageJ software; (C) The cells were treated with AdO (50-500 $\mu \mathrm{g} / \mathrm{mL})$ for $20 \mathrm{~h}$ and then incubated with $1 \mathrm{pM}$ of the AuNPs for $1 \mathrm{~h}$. (D) The average number of phagocytosed AuNPs in fifty cells was analyzed using ImageJ software. The cells with the accumulated AuNPs were examined using dark-field microscopy $(40 \times)$, scale bar $=20 \mu \mathrm{m}$; (E) The cells were treated with AdO $(50 \mu \mathrm{g} / \mathrm{mL})$ for $20 \mathrm{~h}$ and then incubated with $500 \mathrm{nM}$ FL-A $\beta$ for $4 \mathrm{~h}$. The cells with the accumulated FL-A $\beta$ were examined using laser scanning confocal microscopy $(60 \times)$, and the morphology of the cells was shown using differential interference contrast (DIC) images, scale bar $=20 \mu \mathrm{m}$; (F) The average fluorescent intensity of fifty cells was evaluated using ImageJ software. The microscopic images were from three independent experiments. ${ }^{* * *} p<0.001$ indicates significant differences compared with the control group.

\subsection{TLR4 Is Involved in the AdO-Promoted Microglial Phagocytosis}

TLR4 is the most important receptor for uptake and clearance of A $\beta$ in the BV2 cells [26]. To determine whether TLR4 is involved in the AdO-augmented microglial phagocytosis of A $\beta$, we used a TLR4 antibody to block TLR4 as mentioned in the previous reports [27,28]. The results indicated that the addition of the anti-TLR4 antibody suppressed the AdO-induced phagocytosis of FL-A $\beta$ (Figure 7A): The incorporation was significantly less than that of the cells treated with AdO alone (Figure 7B). These results indicated that TLR4 is involved in AdO-promoted microglial phagocytosis. In the merged images (Figure 7A), the distribution of FL-A $\beta$ was observed in the cytoplasm and lysosomes, suggesting that the FL-A $\beta$ had already entered the cells. Furthermore, we conducted a flow cytometry assay to verify this involvement. The flow cytometric plots of the phagocytic cell populations are shown in Figure 7C, and the mean fluorescent intensity (MFI) showed a trend that was consistent with the fluorescence microscopic analysis (Figure 7D). Our flow cytometric assay results further confirmed that TLR4 is involved in the AdO-induced promotion of microglial phagocytosis. Finally, because the lysosomes and cytoskeleton participate in the phagocytotic process [29], we 
evaluated the effect of $\mathrm{AdO}$ on the lysosomes and cytoskeleton of the BV2 cells. Unfortunately, these results demonstrated that $\mathrm{AdO}$ had little effect on the lysosome production and cytoskeleton formation compared with the untreated cells (Figure S2).

A
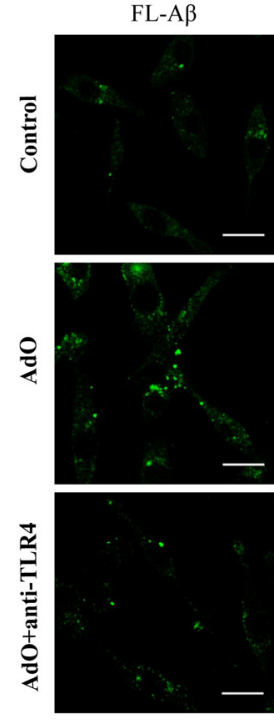

LysoTracker
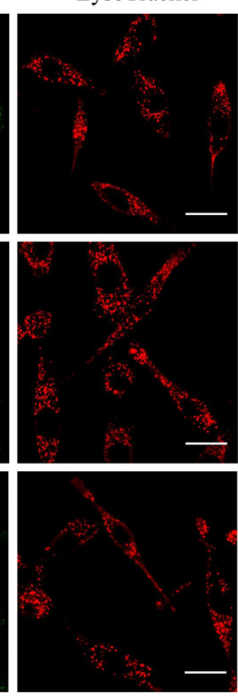

DAPI
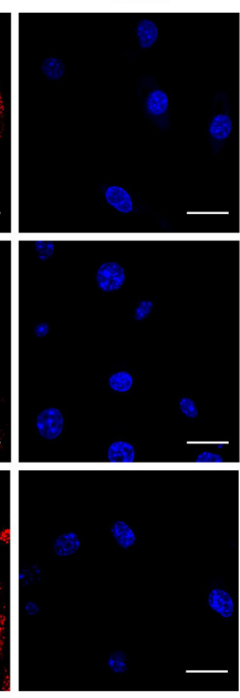

C

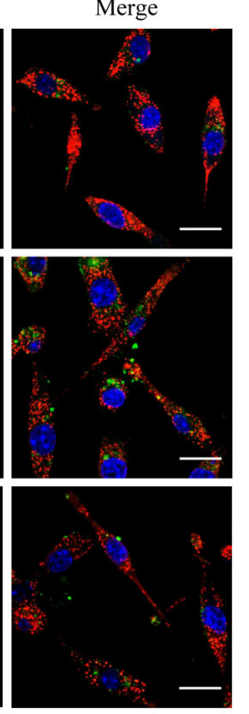

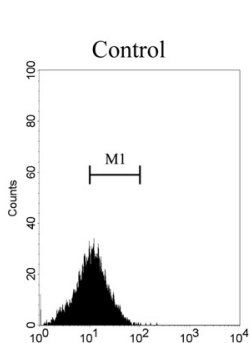
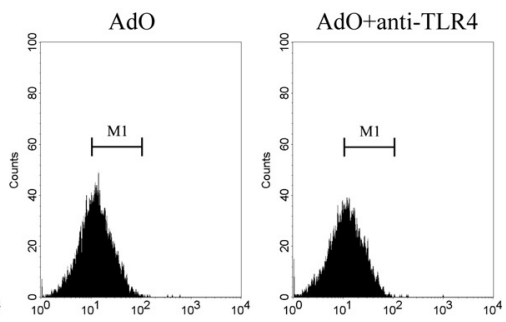

$\mathrm{D}$
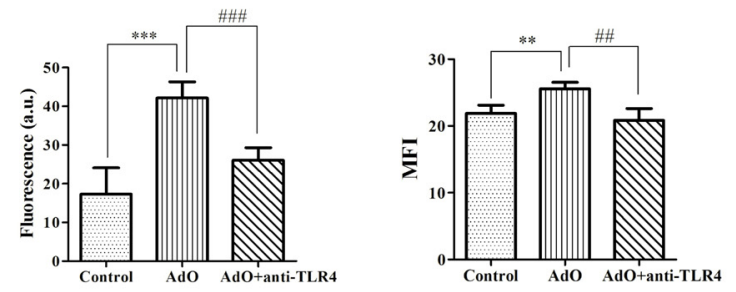

Figure 7. The involvement of TLR4 in the AdO-promoted phagocytosis of A $\beta$ in the BV2 cells. (A) The cells were treated with anti-TLR4 $(10 \mu \mathrm{g} / \mathrm{mL})$ for $1 \mathrm{~h}$ prior to AdO treatment for $20 \mathrm{~h}$ and then incubated with $500 \mathrm{nM}$ FL-A $\beta$ for $4 \mathrm{~h}$. The lysosomes and nuclei of the cells were stained with LysoTracker Red DND-99 and 4',6-diamidino-2-phenylindole (DAPI), respectively. The cells with the accumulated FL-A $\beta$ were observed using laser scanning confocal microscopy $(60 \times)$, scale bar $=20 \mu \mathrm{m}$; (B) The average fluorescence intensity of fifty cells in each group was evaluated using ImageJ software; (C) The phagocytosis of FL-A $\beta$ in untreated cells, AdO-treated cells, and anti-TLR4 and AdO-treated cells was analyzed using flow cytometry. The flow cytometric plots show the M1 region of the phagocytic cell populations based on fluorescence intensity; (D) The mean fluorescence intensity (MFI) of the cells in the M1 region is shown. The images were from three independent experiments. $* * p<0.01$ and $* * * p<0.001$ indicate significant differences between the control group and the AdO-treated group, and \#\# $p<0.01$ and \#\#\# $p<0.001$ indicate significant differences between the AdO-treated group and the AdO combined with anti-TLR4-treated group.

\section{Discussion}

Agents that either inhibit the microglia-mediated neuroinflammation or enhance the microglial phagocytosis would be beneficial to AD therapy [5,12,30]. Numerous studies have demonstrated that natural products play important roles in treating or slowing the progression of neurodegenerative disease [30-32]. However, several natural products were found to exert neuroprotection by simultaneously suppressing microglial activation and promoting microglial phagocytosis. Blueberries have been found to significantly attenuate microglial activation and enhance microglial clearance of 
$\mathrm{A} \beta$ [33]. Curcumin exerts excellent neuroprotection through its anti-inflammatory activity and its promotion of phagocytosis [27]. Therefore, it is significant to find more natural products that appropriately inhibit microglial activation and promote the microglial uptake of $A \beta$. Polysaccharides from natural products exert notable neuroprotective and anti-neuroinflammatory activity [32,34]. Alginate is a natural polysaccharide that is found in various marine brown seaweeds. There have been significant studies in the last few decades that have revealed the bioactivities and broadened the utility of alginate-derived oligosaccharide [13,14]. Previous work has demonstrated that alginate oligosaccharides (1300 Da) prepared by enzymatic depolymerization could easily cross the blood-brain barrier (BBB) [35,36]. We have shown that alginate oligosaccharides prepared by enzymatic and oxidative degradation exhibited similar degree of polymerization (DP) (representative of its molecular mass) using thin-layer chromatography (TLC) analysis in our previous work [18]. The average molecular weight of $\mathrm{AdO}$ is about $1500 \mathrm{Da}$. These findings indicated the accessibility of AdO to the $\mathrm{BBB}$ and suggested the potential application of $\mathrm{AdO}$ for treating neurodegenerative diseases. In our previous study, we found that $\mathrm{AdO}$ could remarkably reduce the production of inflammatory mediators in LPS-activated macrophages [23], which encouraged us to study its anti-neuroinflammatory activity. In the present work, we aimed to evaluate the effects of AdO on the neuroinflammatory responses and microglial phagocytosis of $\mathrm{A} \beta$.

The production of NO and $\mathrm{PGE}_{2}$ and the expression of $\mathrm{iNOS}$ and COX-2 are the most important processes involved in LPS-activated neuroinflammation [34]. Here, we found that AdO pretreatment effectively inhibited the LPS-activated production of $\mathrm{NO}$ and $\mathrm{PGE}_{2}$ via the suppression of the transcriptional activation of iNOS and COX-2 in BV2 cells (Figure 2). Excessive production of pro-inflammatory cytokines is considered to be an initiator of neuroinflammatory responses, which is a hallmark of neurodegenerative disease [37], and to cause neuronal cytotoxicity and induce nerve cell damage. This study proved that AdO-treatment of BV2 cells remarkably inhibited the LPS-activated production of TNF- $\alpha$, IL- 6 and IL- $1 \beta$ as well as the A $\beta$-activated production of TNF- $\alpha$, IL- 6 and IL-12 (Figure 3). These results suggest that AdO may be useful in the treatment of neuroinflammation by suppressing microglial activation and attenuating the production of inflammatory mediators.

It has been demonstrated that TLR4-mediated activation of NF- $\kappa \mathrm{B}$ signaling pathway plays an important role in the neuroinflammatory responses and various neurodegenerative diseases [9]. The current work showed that pretreatment of BV2 cells with AdO could remarkably suppress the LPS-stimulated TLR4 expression, indicating that the TLR4 signaling pathway was involved in the anti-neuroinflammatory effect of $\mathrm{AdO}$ (Figure 4). NF- $\kappa \mathrm{B}$ is kept inactive through the binding of I $\mathrm{B}$ proteins in resting microglial cells. Microglial activation with LPS activates NF- $\kappa B$ signaling, leading

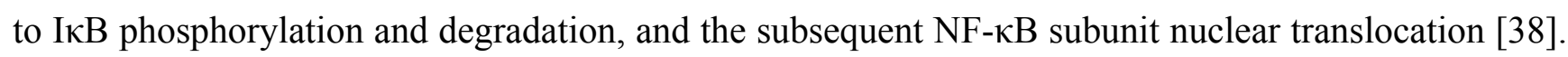
Here, we found that the nuclear translocation of the NF-kB p65 subunit was effectively attenuated by AdO treatment (Figure 4). These findings indicate that the inhibitory effects of AdO on TLR4 expression may involve the inactivation of NF- $\mathrm{KB}$ signaling in LPS-activated BV2 microglia, subsequently leading to the suppression of inflammatory mediator production. In addition, we found that AdO could protect the microglia from the LPS/A $\beta$-activated morphological changes (Figure 5). In either case, these results indicated that the neuroprotective effect of $\mathrm{AdO}$ is mediated by inactivation the TLR4-NF- $\kappa$ B signaling pathway. 
Another key role of microglial cells is their capability to clear toxic A $\beta$ aggregates. $A \beta$ accumulation plays an important role in the progression of AD [3]. Under normal physiological conditions, $A \beta$ aggregates are adequately cleared and degraded by the microglia and macrophages in the brain. Unfortunately, impaired phagocytosis of $A \beta$ by the microglia and macrophages is observed in $\mathrm{AD}$ and is considered to be one of the pathological hallmarks of this disease [39]. After demonstrating the excellent inhibitory effect of $\mathrm{AdO}$ on microglia-mediated neuroinflammation, we further explored the effect of $\mathrm{AdO}$ on the phagocytosis by BV2 cells. Interestingly, we found that AdO treatment promoted the phagocytosis of FL-A $\beta$ (Figure 6). Because TLR4 is directly or indirectly activated to induce the uptake of toxic $A \beta$ aggregates [26,40], we evaluated the involvement of TLR4 in the promotional effect of AdO on the microglial uptake of $A \beta$. Blocking TLR4 with anti-TLR4 prior to AdO treatment resulted in a decrease in the phagocytosis of $\mathrm{A} \beta$, indicating that $\mathrm{AdO}$ promoted phagocytosis through an interaction with TLR4 (Figure 7).

Neuroinflammation and microglial phagocytosis are both important factors to study with respect to the therapeutic intervention for $\mathrm{AD}$ [4]. Therefore, the development of natural products that cannot only inhibit the neuroinflammation but that can also enhance the clearance of $A \beta$ is important for the prevention and treatment of $\mathrm{AD}$. It was interesting to find that $\mathrm{AdO}$ exhibited remarkably inhibitory effect on neuroinflammation and promoted microglial phagocytosis of $A \beta$ in this study. We demonstrated that AdO inhibited the neuroinflammatory response of LPS-activated BV2 cells, possibly by attenuating TLR4 expression and inactivating the NF- $\kappa \mathrm{B}$ signaling pathway. However, the molecular mechanism by which $\mathrm{AdO}$ promoted the phagocytosis of $\mathrm{A} \beta$ is still uncertain. Our results indicated that the AdO-induced promotion of the uptake of A $\beta$ may directly or indirectly involve TLR4. It has been demonstrated that TLR4 participates in the neuroinflammatory process, suggesting that TLR4 activation aggravates neuroinflammation-mediated diseases [41]. In contrast, studies with mice expressing a mutated form of TLR 4 suggested that the activation of microglial TLR 4 could reduce A $\beta$ accumulation [42], indicating that TLR4 activation produced the neuroprotective effect. Whether TLR4 activation is neurotoxic or neuroprotective may differ among the various pathological conditions. The present results support the concept that TLR4 activation is tightly controlled to regulate its different roles in neuroinflammation and microglial phagocytosis. Further studies will focus on the molecular mechanisms of the dual effect of $\mathrm{AdO}$ on microglial cells in depth and explore the therapeutic potential of $\mathrm{AdO}$ in an in vivo model of $\mathrm{AD}$.

\section{Materials and Methods}

\subsection{Materials}

Sodium alginate (15-20 cps grade), FITC-phalloidin and 4',6-diamidino-2-phenylindole (DAPI) were purchased from Sigma-Aldrich (St. Louis, MO, USA). $\mathrm{H}_{2} \mathrm{O}_{2}$ was supplied by Chengdu Kelong Chemical Co., Ltd. (Chengdu, China). Fetal bovine serum (FBS) was obtained from Biontex (Planegg, Germany). Dulbeco's Modified Eagle's Medium (DMEM) was purchased from Thermo Scientific (Hudson, NH, USA). A CCK-8 kit was supplied from Beyotime Inst Biotech (Jiangsu, China). A $\beta$ oligomers were prepared using amyloid- $\beta$ 1-42 peptide (ChinaPeptides Co., Ltd., Shanghai, China) as described previously [25]. An ELISA kit for PGE2 was purchased from Cayman Chemical Co. (Ann 
Arbor, MI, USA). ELISA kits for tumor necrosis factor (TNF)- $\alpha$, interleukin (IL)-1 $\beta$, IL-6 and IL-12 measurement were obtained from Neobioscience Technology Company (Guangdong, China). RNAfast200 Trizol reagent was purchased from Fastagen Biotech (Shanghai, China). The cell lysis buffer was obtained from Biocolors (Shanghai, China). A KeyGEN Nuclear and Cytoplasmic Protein Extraction Kit was purchased from KeyGen Biotech (Nanjing, China). The bicinchoninic acid (BCA) reagent was obtained from Auragene Bioscience Corporation, Inc. (Changsha, China). Antibodies against inducible nitric oxide (iNOS), cyclooxygenase-2 (COX-2) and NF- $\kappa \mathrm{B} / \mathrm{p} 65$, as well as an Alexa Fluor 488-conjugated secondary anti-mouse antibody, were provided by Cell Signaling Technology (Beverly, MA, USA). Antibody against TLR4 was purchased from Abcam Company (Cambridge, UK). Hilyte Fluo $^{\text {TM }}$ 488-labled $\beta$-amyloid (1-42) (FL-A $\beta$ ) was purchased from AnaSpec, Inc. (San Jose, CA, USA) and LysoTracker Red DND-99 was furnished from Molecular Probes (Invitrogen, MO, USA).

\subsection{Preparation of $A d O$}

AdO was prepared from sodium alginate by a reaction with a $5 \% \mathrm{H}_{2} \mathrm{O}_{2}$ solution at $90{ }^{\circ} \mathrm{C}$ for $2 \mathrm{~h}$ as described in our previous work [23]. The average molecular weight of AdO is about $1500 \mathrm{Da}$ that detected by size exclusion chromatography (SEC) with multi-angle laser light scattering (MALLS).

\subsection{Cell Culture}

The BV2 microglia were cultured in DMEM supplemented with $10 \% \mathrm{FBS}, 100 \mathrm{U} / \mathrm{mL}$ penicillin and $100 \mu \mathrm{g} / \mathrm{mL}$ streptomycin at $37^{\circ} \mathrm{C}$ in a humidified incubator with $5 \% \mathrm{CO}_{2}$

\subsection{Cytotoxicity Assay}

The viability of the BV2 cells treated with AdO was evaluated using the CCK-8 assay. Briefly, the cells were pretreated with $\mathrm{AdO}(100-1000 \mu \mathrm{g} / \mathrm{mL})$ for $2 \mathrm{~h}$ and then incubated with LPS/A $\beta$ for $24 \mathrm{~h}$ or treated with AdO (50-1000 $\mu \mathrm{g} / \mathrm{mL})$ for $24 \mathrm{~h}$. The medium was removed and the cells were incubated with $0.5 \mathrm{mg} / \mathrm{mL}$ of the CCK-8 solution. After this incubation, the absorption was measured at $540 \mathrm{~nm}$ using a microplate reader (Molecular Devices, LLC, Sunnyvale, CA, USA).

\subsection{Measurement of $N O$ and $P G E_{2}$}

The BV2 microglia were pretreated with AdO $(50-500 \mu \mathrm{g} / \mathrm{mL})$ for $2 \mathrm{~h}$ and then stimulated with LPS $(0.5 \mu \mathrm{g} / \mathrm{mL})$ for $24 \mathrm{~h}$. The accumulated nitrite in the culture supernatants was measured using the Griess reaction method as described in our previous work [23]. PGE2 production was evaluated using an ELISA kit according to the manufacturer's instructions.

\subsection{Reverse Transcription Polymerase Chain Reaction (RT-PCR)}

RNA was prepared using RNAfast200 Trizol reagent. Total RNA ( $1 \mu \mathrm{g})$ was used for reverse transcription to produce the cDNAs. The iNOS and COX-2 genes were amplified from the cDNA using PCR. The following PCR primers are used in this work: iNOS: Fwd 5'-CAA CCA GTA TTA TGG CTC CT-3'; Reverse 5'-GTG ACA GCC CGG TCT TTC CA-3'. COX-2: Fwd 5'-CCA CTT CAA GGG AGT CTG GA-3'; Reverse 5'-AGT CAT CTG CTA CGG GAG GA-3'. $\beta$-Actin: Fwd 
5'-GGA GAA GAT CTG GCA CCA CAC C-3'; Reverse 5'-CCT GCT TGC TGA TCC ACA TCT GCT GG-3'.

\subsection{Western Blot Analysis}

The BV2 cells were pretreated with AdO for $2 \mathrm{~h}$ and then stimulated with LPS $(0.5 \mu \mathrm{g} / \mathrm{mL})$ for $24 \mathrm{~h}$. The cells were lysed in lysis buffer. To determine the effect of AdO on the nuclear translocation of NF- $\mathrm{BB}$ p65, the nuclear and cytoplasmic proteins were extracted by a KeyGEN Nuclear and Cytoplasmic Protein Extraction Kit. The protein concentrations were determined using the bicinchoninic acid (BCA) reagent. For Western blot analysis, $50 \mu \mathrm{g}$ of proteins was separated by $12.5 \%$ SDS-PAGE. Then, the proteins were transferred onto a polyvinylidene difluoride (PVDF) membrane (Amersham Pharmacia Biotech, England, UK) and subsequently blocked in 10\% skimmed milk in Tris-buffered saline containing $0.1 \%$ Tween 20 (TBST). After the membranes were washed adequately, they were incubated with anti-mouse iNOS (1:1000), anti-mouse COX-2 (1:1000), anti-TLR4 (1:1000), or anti-NF-kB/p65 (1:1000) antibodies in 5\% skimmed milk in TBST at $4{ }^{\circ} \mathrm{C}$ overnight. The membranes were then washed three times with TBST and incubated with a horseradish peroxidase-conjugated secondary antibody at $37{ }^{\circ} \mathrm{C}$ for $2 \mathrm{~h}$. All Western blot assays were performed at least three times.

\subsection{Measurement of Cytokines}

The BV2 microglia were pretreated with AdO $(50-500 \mu \mathrm{g} / \mathrm{mL})$ for $2 \mathrm{~h}$ and then treated with LPS $(0.5 \mu \mathrm{g} / \mathrm{mL})$ or $\mathrm{A} \beta(10 \mu \mathrm{M})$ for $24 \mathrm{~h}$. The levels of TNF- $\alpha$, IL-6, IL-1 $\beta$ and IL-12 were measured using ELISAs according to the manufacturer's protocols.

\subsection{Immunofluorescence Analysis}

TLR4 expression and nuclear localization of NF- $\mathrm{BB} / \mathrm{p} 65$ were detected by immunofluorescence analysis. The BV2 cells $\left(4 \times 10^{5}\right.$ cells/well) were cultured on sterile glass coverslips in 6-well culture dishes. After pretreatment with $\mathrm{AdO}(500 \mu \mathrm{g} / \mathrm{mL})$ and stimulation with $0.5 \mu \mathrm{g} / \mathrm{mL}$ LPS, the cells were fixed with 4\% paraformaldehyde in PBS. Then, the cells were washed with PBS and permeabilized with $0.2 \%$ Triton X-100 in PBS. After $60 \mathrm{~min}$ of incubation with $1 \%(\mathrm{w} / \mathrm{v})$ goat serum in PBS, the cells were incubated with anti-TLR4 or anti-NF- $\kappa$ B p65 antibody diluted in PBS $(1: 200)$ at $4{ }^{\circ} \mathrm{C}$ overnight, washed and then incubated with an Alexa Fluor 488-conjugated secondary anti-mouse antibody for $2 \mathrm{~h}$ at $37{ }^{\circ} \mathrm{C}$. The cells were incubated with DAPI $(5 \mu \mathrm{g} / \mathrm{mL})$ for $15 \mathrm{~min}$ to reveal the nuclei. The immunofluorescence analysis was carried out by a Fluoview FV1000 laser scanning confocal microscope (Olympus, Tokyo, Japan).

\subsection{Cell Morphology}

The BV2 cells $\left(4 \times 10^{5}\right.$ cells/well) were seeded onto coverslips placed in $35 \mathrm{~mm} \times 35 \mathrm{~mm}$ culture dishes. The cells were pretreated with AdO $(50-500 \mu \mathrm{g} / \mathrm{mL})$ and were stimulated with LPS or A $\beta$ for $24 \mathrm{~h}$. Dark-field microscopy was used to examine the cell morphology of BV2 cells using an Olympus BX51 upright optical microscope (Tokyo, Japan). The morphological changes of the cells were 
monitored using a 40× objective, and images were captured using a DP70 camera (Olympus, Tokyo, Japan). Subsequently, the dark field images were analyzed using ImageJ software (National Institutes of Health, Bethesda, USA).

\subsection{Phagocytosis Assay}

AuNPs were prepared as described in our previous work [43]. Briefly, the cells $\left(4 \times 10^{5}\right.$ cells/well $)$ were treated with AdO $(50-500 \mu \mathrm{g} / \mathrm{mL})$ for $20 \mathrm{~h}$. After three washes, the cells were incubated with a solution of $1 \mathrm{pM}$ AuNPs (100 nm diameter) for the indicated times. The cells were then washed, fixed in $4.0 \%(\mathrm{w} / \mathrm{v})$ paraformaldehyde and visualized using dark-field microscopy.

In additional studies, the cells $\left(4 \times 10^{5}\right.$ cells/well $)$ were treated with AdO $(50 \mu \mathrm{g} / \mathrm{mL})$ for $20 \mathrm{~h}$ and incubated with $500 \mathrm{nM}$ FL-A $\beta$ for $4 \mathrm{~h}$. TLR4 was blocked using anti-TLR $4(10 \mu \mathrm{g} / \mathrm{mL})$ at $37{ }^{\circ} \mathrm{C}$ for $2 \mathrm{~h}$ prior to $\mathrm{AdO}$ treatment. To reveal the lysosomes and cytoskeleton of the cells, the BV2 cells were fixed and labeled with LysoTracker Red DND-99 (500 nM) and FITC-phalloidin (800 nM) for $1 \mathrm{~h}$. Then, the cells were observed using a Fluoview FV1000 laser scanning confocal microscope (Olympus, Tokyo, Japan). The fluorescence intensity of the cells was analyzed using ImageJ software.

\subsection{Flow Cytometric Analysis}

The BV2 cells were plated in 24 -well culture plates $\left(1 \times 10^{5}\right.$ cells/well). The cells were pretreated with AdO $(50 \mu \mathrm{g} / \mathrm{mL})$ for $20 \mathrm{~h}$ and then incubated with FL-A $\beta$ for $4 \mathrm{~h}$. TLR 4 was blocked by treating with anti-TLR4 $(10 \mu \mathrm{g} / \mathrm{mL})$ at $37{ }^{\circ} \mathrm{C}$ for $2 \mathrm{~h}$ prior to the $\mathrm{AdO}$ treatment. The flow cytometric measurements were carried out using a fluorescence-activated cell sorting (FACS) system 145 (Becton Deckinson, San Jose, CA, USA). Subsequently, the cells were washed adequately and the fluorescence was compared to untreated controls using a total of 10,000 recorded events for each sample.

\subsection{Statistical Analysis}

The data for all experiments are presented as the means \pm SD. One-way analysis of variance (ANOVA) and Student's t-tests were used to determine any significant differences. $p$ values $<0.05$ were considered to be significant. Each experiment was repeated at least three times.

\section{Conclusions}

Alginate is a natural polysaccharide derived from various kinds of marine brown algae. Previous studies demonstrated that AdO exhibits notably diverse pharmacological activities $[15,16,18,19]$. However, to the best of our knowledge, this is the first work to explore the effect of AdO on microglia-mediated inflammatory responses and microglial phagocytosis of $A \beta$. The results of this study revealed dual effects of AdO on BV2 microglial cells. First, AdO exerted an inhibitory effect on the LPS/A $\beta$-activated inflammatory response, and second, AdO promoted the microglial phagocytosis of $\mathrm{A} \beta$. Therefore, the current work proposed that $\mathrm{AdO}$ is a potentially therapeutic nutraceutical for treating $\mathrm{AD}$ or other neurodegenerative disease. 


\section{Acknowledgments}

We thank to Jiazuan Ni from Shenzhen University and Zhenqing Zhang from Suzhou University for their kind help. This work was supported by the China Postdoctoral Science Foundation (Grant 2014T70825, Grant 2013M540664), the National Natural Science Foundation of China (Grant 31000770), and the Shenzhen Bureau of Science, Technology and Information (Grant JCYJ20130329111455027 and Grant JCYJ20130408172946974).

\section{Author Contributions}

Rui Zhou and $\mathrm{Xu} \mathrm{Xu}$ conceived and designed the experiments; Rui Zhou, Xu-Yang Shi, De-Cheng Bi, Wei-Shan Fang and Gao-Bin Wei performed the experiments; Rui Zhou, De-Cheng Bi, and $\mathrm{Xu} \mathrm{Xu}$ analyzed the data; and Rui Zhou and $\mathrm{Xu} \mathrm{Xu}$ wrote the paper.

\section{Conflicts of Interest}

The authors declare no conflicts of interest.

\section{References}

1. Maccioni, R.B.; Morales, I.; Guzman-Martinez, L.; Cerda-Troncoso, C.; Farías, G.A. Neuroinflammation in the pathogenesis of Alzheimer's disease. A rational framework for the search of novel therapeutic approaches. Front. Cell. Neurosci. 2014, 8, 1-9.

2. Tansey, M.G.; Frank-Cannon, T.C.; McCoy, M.K.; Lee, J.K.; Martinez, T.N.; McAlpine, F.E.; Ruhn, K.A.; Tran, T.A. Neuroinflammation in Parkinson's disease: Is there sufficient evidence for mechanism-based interventional therapy? Front. Biosci. 2008, 13, 709-717.

3. LaFerla, F.M.; Green, K.N.; Oddo, S. Intracellular amyloid-beta in Alzheimer's disease. Nat. Rev. Neurosci. 2007, 8, 499-509.

4. Carret-Rebillat, A.-S.; Pace, C.; Gourmaud, S.; Ravasi, L.; Montagne-Stora, S.; Longueville, S.; Tible, M.; Sudol, E.; Chang, R.C.-C.; Paquet, C.; Mouton-Liger, F.; Hugon, J. Neuroinflammation and $A \beta$ accumulation linked to systemic inflammation are decreased by genetic PKR down-regulation. Sci. Rep. 2015, doi:10.1038/srep08489.

5. Gold, M.; Dolga, A.; Koepke, J.; Mengel, D.; Culmsee, C.; Dodel, R.; Koczulla, A.; Bach, J.-P. $\alpha$-antitrypsin modulates microglial-mediated neuroinflammation and protects microglial cells from amyloid- $\beta$-induced toxicity. $J$. Neuroinflammation 2014, 11, 1-15.

6. Wang, X.X.; Wang, C. M.; Wang, J. M.; Zhao, S. Q.; Zhang, K.; Wang, J.; Zhang, W.; Wu, C.; Yang, J. Pseudoginsenoside-F11 (PF11) exerts anti-neuroinflammatory effects on LPS-activated microglial cells by inhibiting TLR4-mediated TAK1/IKK/NF- $\kappa \mathrm{B}$, MAPKs and Akt signaling pathways. Neuropharmacology 2014, 79, 642-656.

7. Gonzalez-Scarano, F.; Baltuch, G. Microglia as mediators of inflammatory and degenerative diseases. Annu. Rev. Neurosci. 1999, 22, 219-240.

8. Dheen, S.T.; Kaur, C.; Ling, E.A. Microglial activation and its implications in the brain diseases. Curr. Med. Chem. 2007, 14, 1189-1197. 
9. Zhao, M.; Zhou, A.; Xu, L.; Zhang, X. The role of TLR4-mediated PTEN/PI3K/AKT/NF-кB signaling pathway in neuroinflammation in hippocampal neurons. Neurosci. 2014, 269, 93-101.

10. Moore, A.H.; O'Banion, M.K. Neuroinflammation and anti-inflammatory therapy for Alzheimer's disease. Adv. Drug. Deliv. Rev. 2002, 54, 1627-1656.

11. Lucin, K.M.; O’Brien, C.E.; Bieri, G.; Czirr, E.; Mosher, K.I.; Abbey, R.J.; Mastroeni, D.F.; Rogers, J.; Spencer, B.; Masliah, E.; Wyss-Coray, T. Microglial beclin 1 regulates retromer trafficking and phagocytosis and is impaired in Alzheimer's disease. Neuron 2013, 79, 873-886.

12. Smith, A.M.; Gibbons, H.M.; Dragunow, M. Valproic acid enhances microglial phagocytosis of amyloid- $\beta 1-42$. Neuroscience 2010, 169, 505-515.

13. Sun, J.C.; Tan, H.P. Alginate-Based Biomaterials for Regenerative Medicine Applications. Materials. 2013, 6, 1285-1309.

14. Lee, K.Y.; Mooney, D.J. Alginate: Properties and biomedical applications. Prog. Polym. Sci. 2012, 37, 106-126.

15. Iwamoto, Y.; Xu, X.; Tamura, T.; Oda, T.; Muramatsu, T. Enzymatically depolymerized alginate oligomers that cause cytotoxic cytokine production in human mononuclear cells. Biosci. Biotechnol. Biochem. 2003, 67, 258-263.

16. Tusi, S.K.; Khalaj, L.; Ashabi, G.; Kiaei, M.; Khodagholi, F. Alginate oligosaccharide protects against endoplasmic reticulum- and mitochondrial-mediated apoptotic cell death and oxidative stress. Biomaterials 2011, 32, 5438-5458.

17. Eftekharzadeh, B.; Khodagholi, F.; Abdi, A.; Maghsoudi, N. Alginate protects NT2 neurons against H2O2-induced neurotoxicity. Carbohydr. Polym. 2010, 79, 1063-1072.

18. Xu, X.; Wu, X.T.; Wang, Q.Q.; Cai, N.; Zhang, H.; Jiang, Z.; Wan, M.; Oda, T. Immunomodulatory effects of alginate oligosaccharides on murine macrophage RAW264.7 cells and their structure-activity relationships. J. Agri. Food Chem. 2014, 62, 3168-3176.

19. Xu, X.; Bi, D.-C.; Li, C.; Fang, W.-S.; Zhou, R.; Li, S.-M.; Chi, L.-L.; Wan, M.; Shen, L.-M. Morphological and proteomic analyses reveal that unsaturated guluronate oligosaccharide modulates multiple functional pathways in murine macrophage RAW264.7 cells. Mar. Drugs 2015, 13, 1798-1818.

20. Mirshafiey, A.; Khodadadi, A.; Rehm, B.H.; Khorramizadeh, M.R.; Eslami, M.B.; Razavi, A.; Saadat, F. Sodium alginate as a novel therapeutic option in experimental colitis. Scand. J. Immunol. 2005, 61, 316-321.

21. Mo, S.-J.; Son, E.-W.; Rhee, D.-K.; Pyo, S. Modulation of tnf- $\alpha$-induced icam-1 expression, no and h202 production by alginate, allicin and ascorbic acid in human endothelial cells. Arch. Pharm. Res. 2003, 26, 244-251.

22. Yang, Z.; Li, J.; Guan, H. Preparation and characterization of oligomannuronates from alginate degraded by hydrogen peroxide. Carbohydr. Polym. 2004, 58, 115-121.

23. Zhou, R.; Shi, X.Y.; Gao, Y.; Cai, N.; Jiang, Z.D.; Xu, X. Anti-inflammatory activity of guluronate oligosaccharides obtained by oxidative degradation from alginate in lipopolysaccharide-activated murine macrophage RAW 264.7 cells. J. Agric. Food Chem. 2015, $63,160-168$. 
24. Bi, W.; Zhu, L.H.; Jing, X.N.; Zeng, Z.F.; Liang, Y.R.; Xu, A.D.; Liu, J.; Xiao, S.H.; Yang, L.H.; Shi, Q.Y.; Guo, L.; Tao, E.X. Rifampicin improves neuronal apoptosis in LPS-stimulated co-cultured BV2 cells through inhibition of the TLR-4 pathway. Mol. Med. Rep. 2014, 10, 1793-1799.

25. Shukla, S.M.; Sharma, S. Sinomenine inhibits microglial activation by Abeta and confers neuroprotection. J. Neuroinflammation 2011, 8, 1-11.

26. Tahara, K.; Kim, H.D.; Jin, J.J.; Maxwell, J.A.; Li, L.; Fukuchi, K. Role of toll-like receptor signalling in Abeta uptake and clearance. Brain 2006, 129, 3006-3019.

27. He, G.L.; Liu, Y.; Li, M.; Chen, C.H.; Gao, P.; Yu, Z.P.; Yang, X.S. The amelioration of phagocytic ability in microglial cells by curcumin through the inhibition of EMF-induced pro-inflammatory responses. J. Neuroinflammation 2014, 11. 169-174

28. Iwamoto, M.; Kurachi, M.; Nakashima, T.; Kim, D.; Yamaguchi, K.; Oda, T.; Iwamoto, Y.; Muramatsu, T. Structure-activity relationship of alginate oligosaccharides in the induction of cytokine production from RAW264.7 cells. FEBS Lett. 2005, 579, 4423-4429.

29. Underhill, D.M.; Goodridge, H.S. Information processing during phagocytosis. Nat. Rev. Immunol. 2012, 12, 492-502.

30. Wu, W.; Wu, Y.; Huang, H.; He, C.; Li, W.; Wang, H.; Chen, H.; Yin, Y. Biochanin A attenuates LPS-induced pro-inflammatory responses and inhibits the activation of the MAPK pathway in BV2 microglial cells. Int. J. Mol. Med. 2015, 35, 391-398.

31. Essa, M.M.; Vijayan, R.K.; Castellano-Gonzalez, G.; Memon, M.A.; Braidy, N.; Guillemin, G.J. Neuroprotective Effect of Natural Products Against Alzheimer's Disease. Neurochem. Res. 2012, 37, 1829-1842.

32. Teng, P.; Li, Y.H.; Cheng, W.J.; Zhou, L.; Shen, Y.; Wang, Y. Neuroprotective effects of Lycium barbarum polysaccharides in lipopolysaccharide-induced BV2 microglial cells. Mol. Med. Rep. 2013, 7, 1977-1981.

33. Zhu, Y.Y.; Bickford, P.C.; Sanberg, P.; Giunta, B.; Tan, J. Blueberry opposes beta-amyloid peptide-induced microglial activation via inhibition of $\mathrm{p} 44 / 42$ mitogen-activation protein kinase. Rejuv. Res. 2008, 11, 891-901.

34. Park, H.Y.; Han, M.H.; Park, C.; Jin, C.-Y.; Kim, G.-Y.; Choi, I.-W.; Kim, N.D.; Nam, T.-J.; Kwon, T.K.; Choi, Y.H. Anti-inflammatory effects of fucoidan through inhibition of NF-кB, MAPK and Akt activation in lipopolysaccharide-induced BV2 microglia cells. Food Chem. Toxicol. 2011, 49, 1745-1752.

35. Guo, X.L.; Xin, X.L.; Gan, L.; Nie, Q.; Geng, M.Y. Determination of the accessibility of acidic oligosaccharide sugar chain to blood-brain barrier using surface plasmon resonance. Biol. Pharm. Bull. 2006, 29, 60-63.

36. Fan, Y.; Hu, J.F.; Li, J.; Yang, Z.; Xin, X.L.; Wang, J.; Ding, J.; Geng, M.Y. Effect of acidic oligosaccharide sugar chain on scopolamine-induced memory impairment in rats and its related mechanisms. Neurosci. Lett. 2005, 374, 222-226.

37. Smith, J.A.; Das, A.; Ray, S.K.; Banik, N.L. Role of pro-inflammatory cytokines released from microglia in neurodegenerative diseases. Brain. Res. Bull. 2012, 87, 10-20. 
38. Emmanouil, M.; Taoufik, E.; Tseveleki, V.; Vamvakas, S.-S.; Probert, L. A Role for Neuronal $\mathrm{NF}-\kappa \mathrm{B}$ in Suppressing Neuroinflammation and Promoting Neuroprotection in the CNS. In Advances in TNF Family Research; Wallach, D., Kovalenko, A., Feldmann, M., Eds; Springer: New York, NY, USA, 2011; Volume 691, pp. 575-581.

39. Cherry, J.; Olschowka, J.; O'Banion, M. Neuroinflammation and M2 microglia: The good, the bad, and the inflamed. J. Neuroinflammation 2014, 11, 1-15.

40. Michaud, J.P.; Halle, M.; Lampron, A.; Theriault, P.; Prefontaine, P.; Filali, M.; Tribout-Jover, P.; Lanteigne, A.M.; Jodoin, R.; Cluff, C.; et al. Toll-like receptor 4 stimulation with the detoxified ligand monophosphoryl lipid A improves Alzheimer's disease-related pathology. Proc. Natl. Acad. Sci. USA 2013, 110, 1941-1946.

41. Yao, L.L.; Kan, E.M.; Lu, J.; Hao, A.; Dheen, S.T.; Kaur, C.; Ling, E.-A. Toll-like receptor 4 mediates microglial activation and production of inflammatory mediators in neonatal rat brain following hypoxia: Role of TLR4 in hypoxic microglia. J. Neuroinflammation 2013, 10, 1-21.

42. Song, M.; Jin, J.; Lim, J.E.; Kou, J.; Pattanayak, A.; Rehman, J.A.; Kim, H.D.; Tahara, K.; Lalonde, R.; Fukuchi, K. TLR4 mutation reduces microglial activation, increases Abeta deposits and exacerbates cognitive deficits in a mouse model of Alzheimer's disease. J. Neuroinflammation 2011, doi:10.1186/1742-2094-8-92.

43. Zhou, R.; Zhou, H.Y.; Xiong, B.; He, Y.; Yeung, E.S. Pericellular Matrix Enhances Retention and Cellular Uptake of Nanoparticles. J. Am. Chem. Soc. 2012, 134, 13404-13409.

(C) 2015 by the authors; licensee MDPI, Basel, Switzerland. This article is an open access article distributed under the terms and conditions of the Creative Commons Attribution license (http://creativecommons.org/licenses/by/4.0/). 